\title{
Delayed diagnosis and subsequently
} increased severity of acute appendicitis (compatible with clinical-pathologic grounds) during the COVID-19 pandemic: an observational case-control study

Amitai Bickel ${ }^{1,2+}$, Samer Ganam ${ }^{1 \dagger}$, Ibrahim Abu Shakra', Inbal Farkash ${ }^{4}$, Rola Francis ${ }^{1}$, Nour Karra ${ }^{3}$, Fahed Merei ${ }^{1}$, Isaac Cohen ${ }^{4}$ and Eli Kakiashvili ${ }^{1,2^{*}}$

\begin{abstract}
Background: During a global crisis like the current COVID-19 pandemic, delayed admission to hospital in cases of emergent medical illness may lead to serious adverse consequences. We aimed to determine whether such delayed admission affected the severity of an inflammatory process regarding acute appendicitis, and its convalescence.

Methods: In a retrospective observational cohort case-control study, we analyzed the medical data of 60 patients who were emergently and consecutively admitted to our hospital due to acute appendicitis as established by clinical presentation and imaging modalities, during the period of the COVID-19 pandemic (our study group). We matched a statistically control group consisting of 97 patients who were admitted during a previous 12-month period for the same etiology. All underwent laparoscopic appendectomy. The main study parameters included intraoperative findings (validated by histopathology), duration of abdominal pain prior to admission, hospital stay and postoperative convalescence (reflecting the consequences of delay in diagnosis and surgery).

Results: The mean duration of abdominal pain until surgery was significantly longer in the study group. The rate of advanced appendicitis (suppurative and gangrenous appendicitis as well as peri-appendicular abscess) was greater in the study than in the control group ( 38.3 vs. $21.6 \%, 23.3$ vs. $16.5 \%$, and 5 vs. $1 \%$ respectively), as well as mean hospital stay.
\end{abstract}

Conclusions: A global crisis like the current viral pandemic may significantly affect emergent admissions to hospital (as in case of acute appendicitis), leading to delayed surgical interventions and its consequences.

Keywords: Laparoscopic appendectomy, COVID-19, Acute appendicitis

*Correspondence: elik@gmc.gov.il

${ }^{\dagger}$ AmitaiBickel and Samer Ganam have contributed equally to the work

${ }^{1}$ Department of Surgery A, Galilee Medical Center, 22100 Nahariya, Israel

Full list of author information is available at the end of the article

\section{Introduction}

Acute appendicitis is considered one of the most common abdominal emergencies.

Theetiology is diverse and not always clear, and include mucosal ulceration due toenteric infection, foreign bodies, ischemia, and luminal obstruction. The finalcommon pathway of these factors is invasion of the wall of the 
appendix by intraluminalbacteria together with typical inflammatory changes $[1,2]$. It was alreadyreported that short delay until appendectomy, as well as early antibiotictreatment for acute appendicitis, may postpone surgical intervention for awhile [3-7]. However, timing of surgery for appendicitis is of paramountimportance as significant delay may lead to progression of the inflammatoryprocess, propagating from acute catarrhal appendicitis to supurative(phlegmonous), gangrenous and perforated appendicitis, and abscess formation, apossibility of peritonitis and sepsis [3-8]. According to large series, theexpected distribution of the inflammatory process includes severe inflammatorychanges in about $32 \%$, and gangrenous appendicitis in particular in about $13.5 \%$ $[1,7,9-11]$. These distributions may vary considerably according to age, gender, andcomorbidities. As the differential diagnosis is wide, accurate assessment isimportant to prevent delayed diagnosis that could be detrimental, especially inthe elderly with comorbidities $[1,3,7,10]$. The preferred and most accurateimaging modality for appendicitis is abdominal computed tomography (CT). Thissignificantly decreases the rate of false positive diagnosis $[6,12]$. Ultrasound(US) and magnetic resonance imaging (MRI) are more relevant for diagnosticassessment of children and pregnant women [5].

The present COVID-19 pandemic raised deep concerns in the general population that arrival at a hospital could expose people to the viral disease. Fears of being infected has affected behavior even in the presence of a medical necessity [13, 14].

Recent publications have recently addressed the issue of appendicitis during the viral pandemic [15-27]. Several studies have demonstrated reduced admission rate of acute appendicitis due to preferring conservative care by antibiotic treatment at home for mild inflammation [23-27]. Others have shown increased ratio of advanced inflammatory process during the pandemic due to significant admission delay, most probably due to psychological effect [15-22]. As there is a diversity regarding pathologic nomenclature, and as the clinical and the intra-operative presentation of the appendix are not always in accordance with the pathological appearance, we enrolled this retrospective study to show the effects of delayed admission of emergent cases during the COVID-19 pandemic on the severity of the disease, supported by meticulous validation of the clinical presentation with histopathologic findings $[1,2,28]$.

\section{Methods}

We conducted a retrospective observational cohort study of all the patients above 18 years old, who were admitted to the Department of Surgery of Galilee Medical Center, Nahariya, with acute appendicitis that was validated by clinical presentation and imaging modalities (the inclusion criteria). Patients admitted during the main surge of the COVID-19 pandemic (March 1st to June 30th 2020) constituted the study group. The control group consisted of patients who were treated for acute appendicitis during a 12-month period prior to the Corona pandemic (January to December 2019). The study was approved by the institutional Helsinki Committee of the Galilee Medical Center (approval number 0074-20-NHR). In this retrospective file, the approval by the committee included the informed consent (for using all relevant medical information) was obtained from all the relevant participants, without revealing any personal information. The patients' medical files were meticulously explored for medical and laboratory data (gender, age, associated illnesses, the elapsed time since the start of abdominal pain to surgery, intraoperative findings, the surgical approach, the type and duration of antibiotic treatment, hospital stay, perioperative complications, laboratory, pathological, and imaging analysis).

All the surgical interventions were done through the laparoscopic approach. Every gross presentation of the inflamed appendix was validated intra-operatively by an attending and a senior surgeon. All the histopathology findings of the resected specimen were re-evaluated and validated during the conduction of this research by two senior pathologists, for a better definition of the intraoperative findings in cases of controversy. For example, whenever what was seemed to be a suppurative appendicitis on scene while pathologic examination merely exhibited mild inflammatory changes, the category was changed to mild appendicitis, and vice versa.

\section{Statistical analysis}

We used the IBM software SPSS version 25 for statistical analysis. Descriptive statistics in terms of mean, standard deviation (SD), median, and 25-75 percentiles were performed for all the data parameters. Normal distributions of the quantitative parameters were calculated by the Kolmogorov-Smirnov test. According to the results, we used the parametric $t$-test or the non-parametric Mann Whitney $U$ test to define differences between the time periods. We used Fisher's exact test to compare categorical parameters of the two groups. A $p$ value less than 0.05 was considered statistically significant.

\section{Results}

During 6-months along the main surges of COVID19 pandemic period, 60 patients were presented to our department of surgery suffering acute appendicitis. During the 12-months of the control period, 97 patients suffering from acute appendicitis were admitted (Table 1). The mean age of both groups did not differ statistically 
Table 1 Demographic and clinical characteristics, and intrabdominal findings of patients who underwent laparoscopic appendectomy for acute appendicitis, during the COVID-19 pandemic (Study Group), and during a 12- months of the Control Group

\begin{tabular}{lllr}
\hline & Study group; $\mathbf{n = 6 0}$ & Control group; $\mathbf{n = 9 7}$ & $\mathbf{P}$ value \\
\hline Age & $33.0 \pm 15.9$ & $38.4 \pm 16.9$ & \\
Gender & & & \\
$\quad$ Male & $50 \%$ & $46 \%$ & 0.19 \\
$\quad$ Female & $50 \%$ & $59(60.8 \%)$ & $\mathbf{0 . 0 0 8}$ \\
Catarrhal inflammation & $23(38.3 \%)$ & $21(21.6 \%)$ & $\mathbf{0 . 0 2 8}$ \\
Phlegmonous (suppurative) & $23(38.3 \%)$ & $16(16.5 \%)$ & 0.30 \\
Gangrenous & $14(23.3 \%)$ & $1(1.03 \%)$ & 0.15 \\
Peri-appendicular abscess & $3(5 \%)$ & $2.75 \pm 1.51$ & 0.19 \\
Hospital stay (days) & $3.08 \pm 1.57$ & $3.39 \pm 1.85$ & 0.74 \\
Duration of antibiotic treatment (days) & $3.56 \pm 2.08$ & $1.71 \pm 1.39$ & $<\mathbf{0 . 0 0 1}$ \\
Duration of abdominal pain until surgery (days) & $2.56 \pm 1.53$ & & \\
Median: $25-75 \%$ & &
\end{tabular}

( $p=0.19$, Fisher's exact test), as well as the male to female ratios. The clinical presentation and laboratory analysis were not statistically different regarding both two groups. As we focused on intraoperative findings, we did not perform a statistical analysis regarding the imaging (pre-operative) modalities (abdominal ultrasound and computed tomography). Rather, we used it as an adjunct to clarify the clinical and gross presentation of the inflammatory process The mean duration of abdominal pain until surgical intervention (laparoscopic appendectomy) was $2.56 \pm 1.53$ days in the study group and $1.71 \pm 1.39$ days in the control group $(p=0.001,2$-tail Fisher's exact test). The distribution of the gross appearance of the infected appendix, as demonstrated during surgery (and supported by histopathologic analysis) have demonstrated significantly larger rates of phlegmonous (suppurative) appendicitis in the study group, while the proportions of mild (catarrhal) appendicitis were less, as compared with the control group. Regarding the proportions of gangrenous appendicitis and peri-appendicular abscess, it was noticed to be much higher in the study group, although not reaching statistical significance, probably due to relatively small numbers of participants (Table 1). Hospital stay was longer in the study than the control group ( $3.08 \pm 1.57$ days vs. $2.7 \pm 1.51$ days, $p=0.07$, one-tailed Fisher's exact test). Post-operative complications were not recorded in both two groups, as well as cases of post-operative mortality. There was no need to convert laparoscopic surgeries to open.

\section{Discussion}

This case-control study demonstrated the profound psychological effect of a viral crisis (the Corona COVID-19 pandemic) on patients who necessitated advanced medical (surgical) help in the hospital. Specifically, proper treatment (surgical intervention for acute appendicitis) was significantly delayed, as reflected by prolonged pre-admission time period of abdominal pain. This was validated by results in recent studies, including in elderly $[3,7,10,29]$. We decided to investigate this particular medical condition since the consequence of the delayed admission could have been easily evaluated. It should be stressed that our study subjects were not SARS-CoV-2 infected, a fact that might have been associated with increased mortality [30].

The duration of pain prior to surgery was significantly longer in the COVID-19 group, indicating a delay in arrival to the hospital.

We focused on intraoperative findings and clinical parameters that reflect delay in seeking medical attention $[2,6,7]$.

Our assumptions were clearly validated by demonstrating significantly increased ratio of phlegmonous (suppurative) appendicitis in the study group, correlating with duration of pre-admission pain. Gangrenous changes and abscess formation also clearly presented increased (although not significant) rate during the COVID-19 pandemic. In comparison to recent publication regarding this topic, our results were precisely validated and were congruent with histopathology workup [15-25]. For example, we approved suppurative appendicitis only following demonstration of inflammatory infiltrate and micro abscesses all-over the appendix wall $[1,2]$. According to a worldwide survey, it was demonstrated that during the COVID-19 pandemic, non-operative management was more common, as well as the rate of advanced appendicitis, compared with the pre-COVID era [31].

The mean length of hospital stay was significantly longer in the COVID-19 group. The findings demonstrate that psychological motives (which may be based 
on solid evidence regarding the risk of viral infection) may affect (and overcome) medical rationale. The upshot is significant delay in receiving proper medical and surgical care $[12,13]$.

\section{Conclusions}

Understanding the issue of such viral pandemic regarding acute abdominal pain and appendicitis should help promote proper dissemination of information by conventional and social media networks, thus increasing timely treatment. Ultimately, avoiding such postponements reduces the time patients spend in the hospital, which is the motive behind it.

\section{Abbreviations}

CT: Computed tomography; US: Ultrasound; MRI: Magnetic resonance imaging.

\section{Acknowledgements}

Not applicable.

\begin{abstract}
Authors' contributions
AB: made substantial contribution to conception and design and analysis and interpretation of data, participated in drafting of the article and gave final approval of the version to be published. SG: made substantial contribution to conception and design and analysis and interpretation of data, participated in drafting of the article and gave final approval of the version to be published. IAS: made substantial contribution to conception and design and analysis and interpretation of data. IF: performed the histological examination. RF: made substantial contribution to the article, and participated in revised it critically. NK: made substantial contribution to the article, and participated in revised it critically. FM: performed the literature review. IC: performed the histological examination. EK: made substantial contribution to the article, and participated in drafting. All the authors have agreed to be personally accountable for their own contributions and to ensure that questions related to the accuracy or integrity of any part of the work, even ones in which they were not personally involved, are appropriately investigated and resolved, and the resolution documented in the literature. All authors have read and approved the final manuscript.
\end{abstract}

\section{Funding}

The authors received no funding for this work.

\section{Availability of data and materials}

All data generated or analyzed during this study are included in this published article, In case someone would like to request the data, he should contact the corresponding author.

\section{Declarations}

\section{Ethics approval and consent to participate}

The study and all the relevant methods were approved by the institutional Ethics Committee (Helsinki) of the Galilee Medical Center (0074-20-NHR). This approval included the informed consent (for using all medical information) from all the relevant participants, without revealing any personal information, according to the required regulations. We confirm that all methods were performed in accordance with the relevant guidelines and regulations.

\section{Consent for publication}

Written informed consent was obtained from the patients for publication of this Study and any accompanying images. A copy of the written consent is available for review by the Editor of this journal.

\section{Competing interests}

The authors declare that they have no competing interests.

\section{Author details}

${ }^{1}$ Department of Surgery A, Galilee Medical Center, 22100 Nahariya, Israel. ${ }^{2} \mathrm{Fac}-$ ulty of Medicine in the Galilee, Bar-Ilan University, Safed, Israel. ${ }^{3}$ Department of Internal Medicine E, The Chaim Sheba Medical Centre, Tel-Hashomer, Ramat Gan, Israel. ${ }^{4}$ Department of Pathology, Galilee Medical Center, Nahariya, Israel.

Received: 31 July 2021 Accepted: 9 November 2021

Published online: 11 January 2022

\section{References}

1. Carr NJ. The pathology of acute appendicitis. Ann Diagn Pathol. 2000;4:46-58.

2. Bhangu A, Soreide K, Di Saverio S, Assarsson JH, Drake FT. Acute appendicitis: modern understanding of pathogenesis, diagnosis, and management. Lancet. 2015;386:1278-87.

3. Busch M, Gutzwiller FS, Aellig S, Kuettel R, Metzger U, Zingg U. In-hospital delay increases the risk of perforation in adults with appendicitis. World $J$ Surg. 2011;35:16-26.

4. Clyde C, Bax T, Merg A, MacFarlane M, Lin P, Beyersdorf S, et al. Timing of intervention does not affect outcome in acute appendicitis in a large community practice. Am J Surg. 2008:5:22-7.

5. Styrud J, Eriksson S, Nilsson I, Ahlberg G, Haapaniemi S, Neovius G, et al. Appendectomy versus antibiotic treatment in acute appendicitis A prospective multicenter randomized controlled trial. World J Surg. 2006;30:1033-7.

6. Vons C, Barry C, Maitre S, Pautrat K, Leconte M, Costaglioli B, et al. Amoxicillin plus clavulanic acid versus appendicectomy for treatment of acute uncomplicated appendicitis: an open-label, non-inferiority, randomised controlled trial. Lancet. 2011;377:1573-9.

7. Bhangu A, Panagiotopoulou IG, Chatzizacharias N, Rana M, Rollins K, Ejtehadi F, et al. Safety of short, in-hospital delays before surgery for acute appendicitis: multicentre cohort study, systematic review, and metaanalysis. Ann Surg. 2014;259:894-903.

8. Giraudo G, Baracchi F, Pellegrino L, Dal Corso HM, Borghi F. Prompt or delayed appendectomy? Influence of timing of surgery for acute appendicitis. Surg Today. 2013;43:392-6.

9. Marudanayagam R, Williams GT, Rees BI. Review of the pathological results of 2660 appendicectomy specimens. J Gastroenterol. 2006;41:745-9.

10. Kraemer M, Franke C, Ohmann C, Yang Q. Acute appendicitis in late adulthood: incidence, presentation, and outcome. Results of a prospective multicenter acute abdominal pain study and a review of the literature. Langenbeck's Arch Surg. 2000;385:470-81.

11. Andersson RE, Hugander A, Thulin AJG. Diagnostic accuracy and perforation rate in appendicitis: association with age and sex of the patient and with appendicectomy rate. Eur J Surg Acta Chir. 1992;158:374-41.

12. Rao PM, Rhea JT, Novelline RA. Sensitivity and specificity of the individual CT signs of appendicitis: experience with 200 helical appendiceal CT examinations. J Comput Assist Tomogr. 1997;21:686-92.

13. Spinelli A, Pellino G. COVID-19 pandemic: perspectives on an unfolding crisis. Br J Surg. 2020;105:787-9.

14. Galea S, Merchant RM, Lurie N. The mental health consequences of COVID-19 and physical distancing. JAMA Intern Med. 2020;180:817-8.

15. Rajesh SS, Karthik D, Jayalal RJA. Acute appendicitis during COVID19: changing clinical presentation and outcome. Int J Health Sci Res. 2020;10:1-7.

16. Angeramo CA, Dreifuss NH, Schlottmann F, Rotholtz NA. More severe presentations of acute appendicitis during COVID-19. J Gastrointes Surg. 2021;25:1902-4.

17. Finkelstein P, Picado O, Muddasani K, Wodnicki H, Mesko T, et al. A retrospective analysis of the trends in acute appendicitis during the COVID-19 pandemic. J Laparoendosc Adv Surg Tech. 2021;31:243-6.

18. Willms AG, Oldhafer KJ, Conze S, Thasler W, von Schassen C, et al. Appendicitis during the COVID-19 lockdown: results of a multicenter analysis in Germany. Langenbech's Arch Surg. 2021:406:367-75. 
19. Baral S, chhetri RK, Thapa N. Comparison of acute appendicitis before and within lockdown period in COVID-19 era: a retrospective study from rural Nepal. PLoS ONE. 2021;16:e0245137.

20. Zhou Y, Cen LS. Managing acute appendicitis during the COVID-19 pandemic in Jiaxing, China

21. Lee-Archer P, Blackall S, Campbell H, Boyd D, Patel B, McBride C. Increased incidence of complicated appendicitis during the COVID-19 pandemic. J Pediatrics and Child Health 2020;56:1313-14.

22. Velayos M, Munoz-Serrano AJ, Estefania-Fernandez K, Caldas MCS, Lapena $L M$, et al. Influence of the coronavirus 2 (SARS-Cov-2) pandemic on acute appendicitis. An Pediatr (Engl Ed). 2020;93:118-22.

23. Basamh M, Rajendiran A, Chung WY, Runau F, Sangal S. Management of appendicitis during the COVID pandemic: lessons from the first month of the outbreak. Br J Surg. 2020;107:e450-1.

24. Podda M, Pata F, Pellino G, Di Saverio S. Acute appendicitis during the COVID-19 lockdown: never waste a crisis! Br J Surg. 2021;108:e31-2.

25. Ganesh R, Lucocq J, Ekpete O, Ain NU, Lim SK, et al. Management of appendicitis during COVID-19 pandemic: short-term outcomes. Scottish Med J. 2020;65:144-8.

26. Tankel J, Keinan A, Blich O, Koussa M, Helou B, et al. The decreasing incidence of acute appendicitis during COVID-19: a retrospective multicentre study. World J Surg. 2020;44:2458-63.

27. Collard M, Lakkis Z, Loriau J, Mege D, Sabbagh C, et al. Antibiotics alone as an alternative to appendectomy for uncomplicated acute appendicitis in adults: changes in treatment modalities related to the Covid-19 health crisis. J Visc Surg. 2020;157:533-42.

28. van den Boom AL, de Wijkerslooth EML, Mauff KAL, Dawson I, van Rossem CC, Toorenvliet BR, et al. Interobserver variability in the classification of appendicitis during laparoscopy. Br J Surg. 2018;105:1014-9.

29. Lisi G, Campanelli M, Mastrangeli MR, Grande S, Viarengo MA, Garbarino GM, Vanni G, Grande M. Acute appendicitis in elderly during Covid-19 pandemic. Int J Colorectal Dis. 2021. https://doi.org/10.1007/ s00384-021-03959-x.

30. COVIDSurg Collaborative and GlobalSurg Collaborative. Timing of surgery following SARS-CoV-2 infection: an international prospective cohort study. Anaesthesia. 2021. https://doi.org/10.1111/anae.15458.

31. lelpo B, Podda M, Pellino G, Pata F, Caruso R, Gravante G, Di Saverio S, on behalf of the ACIE Appy Study Collaborative. Global attitudes in the management of acute appendicitis during COVID-19 pandemic: ACIE Appy Study. Br J Surg. 2020. https://doi.org/10.1002/bjs.11999

\section{Publisher's Note}

Springer Nature remains neutral with regard to jurisdictional claims in published maps and institutional affiliations.

Ready to submit your research? Choose BMC and benefit from:

- fast, convenient online submission

- thorough peer review by experienced researchers in your field

- rapid publication on acceptance

- support for research data, including large and complex data types

- gold Open Access which fosters wider collaboration and increased citations

- maximum visibility for your research: over $100 \mathrm{M}$ website views per year

At BMC, research is always in progress.

Learn more biomedcentral.com/submissions 